\title{
17. Fossil trackways of the Baynunah Formation
}

Faysal Bibi

Museum für Naturkunde, Leibniz Institute for Evolution and Biodiversity Science,

Invalidenstrasse 43, 10115 Berlin, Germany. faysal.bibi@mfn.berlin

\section{Brian Kraatz}

Western University of Health Sciences, Pomona, CA, USA

Mark Beech

Department of Culture \& Tourism, Abu Dhabi, UAE

Andrew Hill

Department of Anthropology, Yale University, New Haven, CT, USA

Running head: Fossil trackways 


\begin{abstract}
In addition to skeletal remains that record the presence of a diverse vertebrate fauna, the Baynunah Formation also preserves fossil trackways. These are found on deflated surfaces of carbonate-rich beds, mainly at sites located inland from the coast. Footprints, like other trace fossils, may be difficult to assign to particular species, but provide a window onto ancient behavior that is not attainable from skeletal remains alone. Nine sites bearing fossil footprints have been identified to date in the Baynunah Formation. These are presented and described here, most for the first time. The large majority of footprints (and the most easily identifiable) were made by proboscideans, but three trackways belong to a large ungulate, probably a giraffid, and one print may be that of a hippopotamid. The site of Mleisa 1 is particularly important for its remarkable preservation of the passage of a proboscidean herd intersected by the trackway of a large solitary individual, showing that herding behavior, and possibly also sexual segregation, both hallmarks of modern elephants, were already present in late Miocene proboscideans. Given the large areas across which the carbonates of the Baynunah Formation are exposed inland, many more trackways likely remain to be discovered.
\end{abstract}

Running head: Trackways 


\section{Introduction}

The 1999 monograph Fossil Vertebrates of Arabia (Whybrow and Hill 1999) provided the first extensive descriptions of the sites and fossils of the Baynunah Formation, but included no mention of fossil trackways. Since its publication, a number of trackway sites have been discovered in the inland regions of the Al Gharbia region (Fig. 17.1), where the picturesque outcrops of the coast give way to a low-relief landscape with extensive exposures of the carbonates of the upper Baynunah Formation. The majority of fossil remains from the Baynunah Formation derive from the sandy fluvial beds in its lower parts, while the upper parts are dominated by lower-energy sediments and alternating carbonate and silty beds with few skeletal fossils (see Schuster this volume). However, these lower energy conditions, particularly the carbonate-rich microbial mat deposits, appear to have been well suited for the preservation of vertebrate footprints (in addition to ostracods and pollen, see Mazzini \& Kovacova this volume).

Fossil trackways from the Baynunah were first reported by Higgs et al. (2003; 2005), who provided the first descriptions of the sites of Mleisa 1 and Niqa. They were followed by Bibi et al. (2012) who provided a fuller description of the Mleisa 1 site, interpreting it to represent the oldest evidence for complex social structure in proboscideans, similar to that seen in modern elephants. A critical part of this work was the generation of an aerial photomosaic of the entire site using kite aerial photography, which provided a means to identify, trace, and measure the individual trackways on an image in a way that would have been impossible on the ground. Aerial photography has since figured strongly in the study of these trackway sites, and this chapter presents two new photomosaics.

Fossil trackways provide insights into the behavior of extinct species, evidence that often cannot be deduced from skeletal remains. However it is generally difficult, if not impossible, to identify the exact species that made the prints. The large majority of recognizable footprints in the Baynunah Formation are those of proboscideans, characterized by their large size, round shape, and the intense compression and deformation of the underlying substrate. Modern elephant forefoot prints are round and large, while hindfoot 
prints are oval and smaller, and the anterior parts of the prints are deepest and usually have the largest amount of sediment displaced in front of them (Sanders, this volume).

Unfortunately, the substrate the prints were made in appears not to have been ideal for the preservation of the details of foot anatomy. Comparisons to studies of footprints in modern microbial mats suggest the poor definition of the trackways may be due to the retention of water in the sediment immediately underlying trackway level (Marty et al. 2009). The distinction between manus and pes prints, and the determination of the direction of travel, has so far not been possible for any of the Baynunah trackways.

At Mleisa 1, as at most of the other sites, fossil trackways tend to be preserved in a finely laminated carbonate that is silty to sandy, and that displays wide desiccation cracks and a bioturbated upper surface, pointing to a microbial mat origin (Bibi et al. 2012; Schuster this volume). The depositional environment is reconstructed as a wide, ephemeral, flat-bottomed, and very shallow water body that covered a wide area and supported microbial mat growth. Fossil ostracods indicate that these algal mats formed in shallow freshwater ponds that would subsequent evaporate, creating brackish conditions (Mazzini \& Kovacova this volume). Once dry, microbial mats become too elastic or rigid to further register footprints and also become resistant to rehumidification (Marty et al. 2009). Desiccation cracks in these microbial mats generally have the spaces between them filled by carbonate, indicating repeated cycles of desiccation and humidification, without reactivation or remodeling of the underlying sediments. Thus, any particular trackway level must have been imprinted in a relatively short time between the initial desiccation and the final drying and consolidation of the underlying microbial mat. Given the high precipitation seasonality evidenced from stable isotope data (Uno and Bibi this volume), flooding of these Baynunah environments was probably seasonal and annual, stimulating the growth of new microbial mats and the deposition of new layers of carbonate-rich muds on a yearly basis.

While at least three, possibly four, species of proboscideans have been identified from the Baynunah Formation (Sanders this volume), it is not possible to ascertain which of these (if any) was the maker of any particular trackway. All three species - Stegotetrabelodon 
emiratus, Deinotherium aff. bozasi, and Tetralophodon sp. - spanned the range of sizes observed in the trackway stride lengths. However, the stegotetrabelodont is by far the most abundant of the three, and is probably the most likely candidate for the track maker (Sanders et al. 2010; Sanders, this volume). The phylogenetic position of Tetralophodon and Stegotetrabelodon close to the most recent common ancestor of extant elephants means that both these extinct forms were likely to have possessed the same complex social behaviors typical of their extant relatives. Deinotherium is significantly more basal, however, and while it might also have exhibited complex, sexually-segregated social structure, there is currently no reason to assume that it did.

Body mass estimates for track makers using stride lengths (below) suggest that the Baynunah proboscideans were the size of the largest extant African elephants. These are very likely to be underestimates, however, as postcranial remains from the Baynunah (and of similar species elsewhere) indicate body masses much larger than those of modern elephants (Sanders this volume).

FIGURE 17.1 HERE [Width $=1.5$ columns]

\section{Methods}

Track sites were imaged by kite (MLS 1, BIM) and drone (BGH) aerial photography. The Mleisa 1 photomosaic is an accurate composite that was corrected by actual field measurements (assembly detailed in Bibi et al. 2012). Photomosaics for BGH and BIM were assembled in Agisoft Photoscan 1.4.5 using default options and visually compared to the raw images to assess accuracy. However, these were not corrected using field measurements. Track stride measurements (Table 17.1) for MLS 1 were taken digitally on the photomosaic as reported in Bibi et al. (2012), while all other sites are reported as field measurements. These were taken using measuring tape from the center point (as best determined) of each print. Stride length is the distance between consecutive prints made by the same foot, measured from the print center. Straddle is the width of the trackway, measured perpendicular 
to projected parallel lines connecting the outer edges of the left and right prints. Boxplots were made in $\mathrm{R}$ ( $\mathrm{R}$ Core Team 2018). The proboscidean stride length to body mass regression for Fig. 17.3 was taken from Bibi et al. (2012), which was calculated using stride lengths of living African and Asian elephants (data kindly provided by J. Hutchinson). The regression equation is $\mathrm{m}=164.03 \mathrm{x} \mathrm{s}^{3.0513}$ where $\mathrm{m}$ is mass in kilograms and $\mathrm{s}$ is stride length in meters.

\section{The Trackway Sites}

\section{Bida' al-Ghinia (BGH)}

BGH 1 is a carbonate exposure bearing proboscidean trackways, encompassing an area of roughly 65 x 40 meters, discovered by Mubarak bin Hazeem and visited by our team in December 2017 (Fig. 17.1). An aerial image of BGH 1 is shown in Figure 17.2. Proboscidean footprints are abundant on the surface, but many of these cannot be confidently traced out into trackways. Inspection of the site on the ground and through the aerial image allows the identification of at least 7 trackways (Fig. 17.2), making this the largest concentration after the site of Mleisa 1. However, unlike at Mleisa 1, the tracks at BGH are oriented in different directions and widely dispersed, indicating that these individuals crossed the landscape in separate events and alone, or at most as a pair (e.g. T6 and T7), but not as a herd.

Stride distances for the BGH trackways are given in Table 17.1 and shown in Fig. 17.2. These include three individuals that exceeded the size of the large, solitary trackway from Mleisa 1 (BGH1 T1, T4, T5), one individual of intermediate size (T2), and three individuals of much smaller size (T3, T6, T7). Body mass estimates based on stride lengths suggest a range of $1800-2500 \mathrm{~kg}$ for the three smallest individuals, around $4000 \mathrm{~kg}$ for an intermediate sized individual, and close to $6000 \mathrm{~kg}$ for the three largest individuals, which is in the range of the largest extant elephants (Fig. 17.3). The three smaller individuals are of similar stride length to the smaller, probably subadult, individuals in the Mleisa 1 herd (below). If we conclude that BGH T3, T6, and T7 - on account of their being solitary represent male individuals, then these would be subadult males that had not yet reached adult 
size. Today, elephant males leave their family units as adolescents, at an average age of 14 in African elephants (Lee et al. 2011), or 10-12 in Asian elephants (de Silva et al. 2013).

However, in both African and Asian elephants, males do not noticeably exceed the size of adult females until they are 20 years old or older (Lee et al. 2011; Mumby et al. 2015). Such an interpretation for the BGH tracks is of course speculative, but warranted in light of the presence of herd structure at Mleisa 1 (below). It would require that the prints at Mleisa and BGH were made by the same species, and by individuals moving at similar speeds.

FIG 17.2 HERE. [Full page width]

FIG 17.3 HERE [Half-page width]

\section{Bida' Al Mutawi'a (BIM)}

BIM 4 is a small carbonate exposure located about $35 \mathrm{~km}$ south of Jebel Barakah, near the town of Bida' Al Mutawi'a. A large number of circular depressions are visible on the site surface, but many of these might be erosional features, lacking the regularity of pace and stride that characterize a trackway. There are, however, two clearly identifiable proboscidean trackways preserved, both oriented southeast-northwest (Fig. 17.4). The close proximity and similar orientation makes it possible that these two individuals were walking together. Stride data indicate that the larger of these (BIM4 T1) was of similar size to the largest individual in the Mleisa 1 herd, and at least as large as a male African elephant (4000-5000 kg, Fig. 17.3, Table 17.1).

FIGURE 17.4 HERE [Full page width]

\section{Jebel Mimiyah (MIM)}

Just east of the town of Mirfa, quarried faces of a low hill provide some of the clearest exposures of Baynunah Formation sediments. Numerous skeletal fossils have been collected from the main hill, designated as site MIM 1, and to the west of this lies a lower outcrop 
designated as MIM 2. A visit by our team to MIM 2 in December 2017 revealed circular features that almost certainly represent proboscidean footprints. This would make MIM 2 the only trackway site known from the coastal area and from within the lower Baynunah Formation and in close proximity to fluvial layers preserving skeletal fossils (including proboscideans). The majority of the circular features at MIM 2 are not immediately recognizable as footprints, and cannot be confidently traced out into trackways, but a set of prints at the eastern end of the site includes a minimum of six consecutive paces that quite convincingly indicate a trackway (though no stride measurements were attempted).

The MIM 2 prints are generally round, of similar size to proboscidean prints from other Baynunah sites, and with signs of downward compression including concave surfaces with a raised outer rim. The prints are often more erosion-resistant than the surrounding matrix and exhibit a characteristic concentric 'onion-ring' structure indicative of laminated substrate deformation, similar to that described for sauropod footprints (Thulborn 2012). Fine micro-stratification is suggestive of microbial mat deposition as at other trackway sites (e.g. Mleisa or BGH), though the sediment does not exhibit the wide cracks and isolated and displaced polygons typical of the microbial mat lithology at Mleisa 1. Aerial imaging of this site in future would provide further information.

\section{FIGURE 17.5 HERE [FULL PAGE WIDTH]}

\section{Mleisa (MLS)}

The area of Mleisa is located about $20 \mathrm{~km}$ south of the coast from Gerain Al Aysh. MLS 1 is a large deflated surface that preserves the trackways of a proboscidean herd and a solitary individual (Figs. 17.6A and B). The site was brought to the attention of archaeologists in 2001 by Mubarak bin Rashid Al Mansouri, and was first described by Higgs et al. (2003) then further described and documented by Bibi et al. (2012) (see also Beech and Higgs 2005; Higgs 2005; Higgs et al. 2005). The MLS 1 herd trackways are preserved for a distance of over 190 meters and that of the solitary individual for over 260 meters. The herd comprises a 
minimum of 13 individuals which is similar to family units of the savanna-dwelling African elephant (Loxodonta africana), rather than the smaller groups of the forest elephant L. cyclotis or the Asian Elephas maximus (Roca et al. 2015). Stride lengths and directionality of the herd trackways show quite a bit of variation, while those of the solitary trackway are very consistent, which agrees with an individual walking alone and not interacting with others. The herd individuals have estimated masses of $\sim 2500-5000 \mathrm{~kg}$ (Fig. 17.3), though they also include what was likely a juvenile $(\sim 1000 \mathrm{~kg}, \mathrm{~T} 18)$. At $\sim 5400 \mathrm{~kg}$, the body mass estimate for the solitary trackway $(\mathrm{T} 1+2)$ is slightly larger than that of the largest individual in the herd. This fits expectations from modern elephants, in which mature males are generally larger and solitary, while adult females and juveniles live in family units. The trackways preserved at Mleisa 1 indicate the presence of complex social behavior in late Miocene proboscideans as seen in elephants today.

As mentioned by Bibi et al. (2012), the fact that the MLS 1 solitary individual is only slightly larger than the largest individual in the herd implies either that the level of body size sexual dimorphism was lower than that in modern elephants, or that the solitary male had not yet reached full adult size. Some of the newly described solitary trackways from BGH 1 have much larger stride lengths, and support the idea that the MLS 1 solitary individual might not yet have attained full body size (assuming these were all made by the same species).

Many of the proboscidean prints at Mleisa 1 have a characteristic morphology with a central concave dish embedded inside the print (Fig. 17.7C-G). This dish has a free rim and is not connected to the side walls of the print, and is probably the result of downward compression and puncturing of the uppermost microbial mat in the trackway layer (see Thulborn, 2012 for similar features in sauropod trackways). The substrate surrounding the print typically shows widely separated polygons typical of microbial mat desiccation (Bibi et al. 2012; Schuster this volume), often with clear signs of displacement outward from the print. Many prints are lacking the central dish (Fig. 17.7H) and it is not clear whether this is due to it never having been there (local variations in the original substrate) or to loss by erosion. The general surface at MLS 1 is quite scoured by wind erosion, and many prints are barely 
discernible. Around the edges of the site, particularly at the southern end, the main trackway layers are partially eroded away, but the individual prints are preserved as more erosionresistant pedestals, presumably on account of compaction having increased their resistance to erosion (Fig 17.7B; cf. Thulborn 2012, figs 5c and 21). Latex molds of two of the betters prints were taken in December 2007 (Fig. 17.7 C-D), and these are housed at the Yale Peabody Museum.

Three non-proboscidean trackways are also preserved at MLS 1 (mentioned but not described by Bibi et al. 2012). These are labelled u1 to u3 in Fig. 17.6B. The longest of these is $\mathrm{u}$, which continues to the south beyond the extent shown in Fig 17.6B. Trackway sections $\mathrm{u} 2$ and $\mathrm{u} 3$ might have been made by the same individual, based on overall orientation as well as similar stride lengths (Fig. 17.3; Table 17.1). The $\mathrm{u} 1-\mathrm{u} 3$ prints are highly eroded and no pedal features can be discerned, but they are much smaller than the proboscidean prints, lack the circular outline and heavily compressed and displaced underlying surface, and the trackway is narrower. Consistencies in the straddle and stride lengths of $\mathrm{u} 1-\mathrm{u} 3$ suggest that they were likely made by the same species. Assuming they were walking, not running, the MLS 1 ungulate trackway stride lengths ( $160-200 \mathrm{~cm}$, Fig. 17.3) are greater than those of the largest living bovids (145-157 cm for African buffalo, eland, wildebeest), but smaller than those of savanna giraffe (247 cm, Cumming and Cumming 2003). Skeletal remains from the Baynunah document a minimum of three giraffid species (Bibi this volume). One of these, known from a partial skeleton assigned to Palaeotragus $\mathrm{cf}$. germaini, was larger than any extant bovid, and of similar dental size to a modern giraffe, but with less elongated limbs, and probably of appropriate size for the MLS 1 ungulate trackways.

MLS 2 is a wide surface exposure about $9 \mathrm{~km}$ east of MLS 1. It preserves numerous proboscidean prints, though these have not been confidently associated into trackways, in addition to a single ungulate trackway similar to those at MLS 1. The MLS 2 ungulate trackway sediments are relatively smooth and not severely degraded by desiccation cracking and post-exposure erosion as at MLS 1, but the prints themselves still lack any obvious features that might enable a more precise identification of the track maker. It was made by an 
animal of similar stride length to the MLS $1 \mathrm{u} 1$ trackway (Fig. 17.3). The straddle of the MLS 2 track is $39-48 \mathrm{~cm}$ (measured in four places). By comparison, the straddle of several of the MLS 1 herd proboscideans ranges between 77 and $150 \mathrm{~cm}$. Latex molds of two of the MLS 2 ungulate prints were taken in December 2007, and these are housed at the Yale Peabody Museum.

FIGURE 17.6A and 17.6B HERE [Full page width EACH or as poster fold-out if possible] FIGURE 17.7 near here [Full page width] FIGURE 17.8 near here [Full page width]

\section{Niqa}

The site of Niqa (NIQ 3 - NIQ 1 and 2 are archaeological sites of much younger age located within the Niqa 3 area) is a large surface exposure located about $15 \mathrm{~km}$ northeast of Ghayathi. The surface itself is strongly undulating and pock-marked with circular features (Fig. 17.9A), but none of these could be securely identified as footprints or associated into trackways. Thulborn (2012) illustrated a very similar-looking site, at which the surface undulations were interpreted as the result of sedimentary displacement by walking sauropods. Further investigation may reveal whether these features at Niqa might be the products of proboscidean movement. Alternately, the undulations might be related to microbial mat growth associated with the deposition of the carbonate-rich sediments.

Higgs et al. (2005) figured three possible footprints from Niqa that they attributed to an animal with a five-toed foot. The better preserved of these (Fig. 17.9B, and Higgs et al. 2005 fig. 3) appears in fact to be four-toed and resembles the swim-track of a hippopotamus, similar to those described by Bennet et al. (2014) from Pleistocene deposits in Kenya (specifically their 'Type Four' tracks; see also Altamura et al. 2017).

Higgs et al. (2005) reported foot width as around $28 \mathrm{~cm}$, which might represent the total width of an eroded print, but the actual foot size was unlikely to have been wider than 20 cm (Fig. 17.9B). This is smaller than the print of a modern adult hippopotamus, but may be 
appropriate for the Baynunah hippopotamid Archaeopotamus qeshta, which is smaller (Boisserie \& Bibi this volume). The Niqa print is unfortunately isolated, and not associated with a trackway from which more confident inferences could be made. The two other prints figured by Higgs et al. (2005, their fig. 2), if that is what they are, might also belong to a hippopotamid.

FIGURE 17.9 HERE [Full page width]

\section{Shahriya (SHA)}

SHA 1 is an exposed surface preserving highly weathered proboscidean trackways, discovered by Ahmad El Hajj and Jaber el Merri in 2007 but only visited by our team in 2017. The southern end of the site has a large assemblage of proboscidean footprints of various sizes (Fig. 17.10). The area is not large, but the number of individual trackways exposed here may rival that at Mleisa 1, potentially making this a second site with evidence for herding behavior. Unfortunately the surface is so heavily eroded by wind action that the trackways are impossible to trace out confidently on the ground. Future attempts to document the site aerially should provide more information.

FIGURE 17.10 HERE. [Full page width]

\section{Umm al Kabir (UAK)}

Northwest of Mleisa and east of the road from the coastal highway to Ghayathi lies the area of Umm al Kabir (alternately Umm al-Khabir), first discovered by Steve Raynor and the Emirates Natural History group on a trip to the nearby Mleisa 1 site in December 2006. UAK 1 and 2 are deflated surfaces exposing an indurated carbonate-rich green silt preserving what appear to be proboscidean prints preserved in relief (Fig. 17.11). Rather than being concave depressions in the ground, these prints take the form of circular, domed pedestals rising above the surrounding surface and exhibiting a consistent pace pattern, strongly suggesting that they 
are footprints rather than an anomalous geological feature. The pedestals themselves lack any sign of lamination or other features indicative of microbial mats, and in this and other features they differ from the pedestaled prints described above from Mleisa 1. The pedestaled prints at UAK are rather more likely to be durable sedimentary fillings (natural casts) of proboscidean prints that formed under different environmental conditions than the microbial mat carbonates at Mleisa 1.

No measurements were taken at UAK 1 or 2 , but one of the tracks at UAK 1 was noted to be about $1 \mathrm{~m}$ wide (straddle), with a stride length of around $3.4 \mathrm{~m}$, placing it in the range of the largest individuals from BGH. The UAK prints are fairly scattered and may represent several solitary individuals.

Fossil eggshell, tooth enamel, and crocodile fragments were collected close to UAK 1 , making it the only inland trackway site that preserves tracks in direct proximity to skeletal remains of typical Baynunah taxa, thereby confirming the stratigraphic link between the two (see supplementary material in Bibi et al. 2012).

FIGURE 17.11 HERE [One column width]

\section{Conclusions}

The fossil footprints of the Baynunah Formation provide an additional window onto the vertebrate fauna of the Arabian Peninsula during the late Miocene. As traces of behavior, trackways have an immediacy and a capacity to evoke the past in a way that skeletal remains do not. In many cases, fossil trackways provide information on the biology of extinct species that could not have been gleaned from the body fossils alone.

In the case of the Baynunah, nine footprint sites have been identified that record proboscidean as well as possible giraffid and hippopotamid tracks, and that significantly enrich the fossil record of the Arabian late Miocene. Among these sites, Mleisa 1 is globally unique in providing clear evidence for complex social behavior in late Miocene 
proboscideans. The sheer aerial extent of the carbonate surface exposures in western Abu Dhabi Emirate suggests that many more trackway sites remain to be discovered there.

\section{Acknowledgments}

We thank Waleed Awad Omar and Nathan Craig for assistance acquiring aerial imagery, and the locals and officials who discovered the trackway sites and alerted us to their existence, including Mubarak bin Hazeem, Ahmad El Hajj, and Jaber el Merri. Funding for this work came primarily from the Abu Dhabi Department of Culture and Tourism (including its previous incarnations). Peter Falkingham, Bill Sanders, and Phyllis Lee provided comments that greatly improved this manuscript.

[TABLE 17.1 HERE]

\section{References}

Altamura, F., Melis, R. T., \& Mussi, M. (2017). A Middle Pleistocene hippo tracksite at Gombore II-2 (Melka Kunture, Upper Awash, Ethiopia). Palaeogeography, Palaeoclimatology, Palaeoecology, 470, 122-131.

Beech, M., \& Higgs, W. (2005). A new late Miocene fossil site in Ruwais, Western Region of Abu Dhabi, United Arab Emirates. In P. Hellyer, \& M. Ziolkowski (Eds.), Emirates Heritage Volume 1 (pp. 6-21). Abu Dhabi: Zayed Centre for Heritage and History.

Bennett, M. R., Morse, S. A., \& Falkingham, P. L. (2014). Tracks made by swimming Hippopotami: An example from Koobi Fora (Turkana Basin, Kenya). Palaeogeography, Palaeoclimatology, Palaeoecology, 409, 9-23, doi:https://doi.org/10.1016/j.palaeo.2014.04.021.

Bibi, F., Kraatz, B. P., Craig, N., Beech, M., Schuster, M., \& Hill, A. (2012). Early evidence for complex social structure in Proboscidea from a late Miocene trackway site in the United Arab Emirates. Biology Letters, 8(4), 670-673. 
Bibi, F. (this volume). Bovidae and Giraffidae from the Baynunah Formation. In F. Bibi, B. Kraatz, M. Beech, \& A. Hill (eds.) Sands of Time: Late Miocene Fossils from the Baynunah Formation, U.A.E. (pp. xxx). Cham: Springer.

Boisserie, J.-R. \& Bibi., F. (this volume). Hippopotamidae from the Baynunah Formation. In F. Bibi, B. Kraatz, M. Beech, \& A. Hill (eds.) Sands of Time: Late Miocene Fossils from the Baynunah Formation, U.A.E. (pp. xxx). Cham: Springer.

Cumming, D. H. M., \& Cumming, G. S. (2003). Ungulate community structure and ecological processes: body size, hoof area and trampling in African savannas. Oecologia, 134(4), 560-568.

de Silva, S., Webber, C. E., Weerathunga, U. S., Pushpakumara, T. V., Weerakoon, D. K., \& Wittemyer, G. (2013). Demographic Variables for Wild Asian Elephants Using Longitudinal Observations. PLoS ONE, 8(12), e82788, doi:10.1371/journal.pone.0082788.

Higgs, W. (2005). The Fossil Trackway at Mleisa. In M. Beech, \& P. Hellyer (Eds.), Abu Dhabi 8 Million Years Ago: Late Miocene Fossils from the Western Region (pp. 37-41). Abu Dhabi: Abu Dhabi Islands Archaeological Survey.

Higgs, W., Gardner, A., \& Beech, M. (2005). A fossil proboscidean trackway at Mleisa, Western Region of Abu Dhabi, United Arab Emirates. In P. Hellyer, \& M. Ziolkowski (Eds.), Emirates Heritage Vol. 1 - Proceedings of the 1st Annual Symposium on Recent Palaeontological and Archaeological Discoveries in the Emirates (pp. 21-27). Al Ain: Zayed Centre for Heritage and History.

Higgs, W., Kirkham, G., Evans, G., \& Hull, D. (2003). A Late Miocene Proboscidean trackway from Mleisa, United Arab Emirates. Tribulus, 13, 3-8.

Lee, P. C., Poole, J. H., Moss, C. J., \& Njiraini, N. (2011). Male social dynamics: Independence and beyond. In C. J. Moss, H. Croze, \& P. C. Lee (Eds.), The Amboseli Elephants: A Long-Term Perspective on a Long-Lived Mammal (pp. 260-271). Chicago: University of Chicago Press. 
Marty, D., Strasser, A., \& Meyer, C. A. (2009). Formation and taphonomy of human footprints in microbial mats of present-day tidal-flat environments: Implications for the study of fossil footprints. Ichnos, 16, 127-142.

Mazzini, I. \& Kovacova, M. (this volume). Ostracods, charophytes, and pollen from the Baynunah Formation. In F. Bibi, B. Kraatz, M. Beech, \& A. Hill (eds.) Sands of Time: Late Miocene Fossils from the Baynunah Formation, U.A.E. (pp. xxx). Cham: Springer. Mumby, H. S., Chapman, S. N., Crawley, J. A. H., Mar, K. U., Htut, W., Soe, A. T., et al. (2015). Distinguishing between determinate and indeterminate growth in a long-lived mammal. BMC Evolutionary Biology, 15(1), 214.

R Core Team (2018). R: A language and environment for statistical computing. R Foundation for Statistical Computing, Vienna, Austria.

Roca, A. L., Ishida, Y., Brandt, A. L., Benjamin, N. R., Zhao, K., \& Georgiadis, N. J. (2015). Elephant Natural History: A Genomic Perspective. Annual Review of Animal Biosciences, 3(1), 139-167, doi:10.1146/annurev-animal-022114-110838.

Sanders, W. J., Gheerbrant, E., Harris, J. M., Saegusa, H., \& Delmer, C. (2010). Proboscidea. In L. Werdelin, \& W. J. Sanders (Eds.), Cenozoic Mammals of Africa (pp. 161-251). Berkeley: University of California Press.

Sanders, W. J. (this volume). Proboscidea from the Baynunah Formation. In F. Bibi, B. Kraatz, M. Beech, \& A. Hill (eds.) Sands of Time: Late Miocene Fossils from the Baynunah Formation, U.A.E. (pp. xxx). Cham: Springer.

Schuster, M. (this volume). Sedimentology and Stratigraphy of the Baynunah Formation. In F. Bibi, B. Kraatz, M. Beech, \& A. Hill (eds.) Sands of Time: Late Miocene Fossils from the Baynunah Formation, U.A.E. (pp. xxx). Cham: Springer.

Thulborn, T. (2012). Impact of Sauropod Dinosaurs on Lagoonal Substrates in the Broome Sandstone (Lower Cretaceous), Western Australia. PLoS ONE, 7(5), e36208, doi:10.1371/journal.pone.0036208. 
Uno, K. \& Bibi, F. (this volume). Stable isotope paleoecology of the Baynunah Formation. In F. Bibi, B. Kraatz, M. Beech, \& A. Hill (eds.) Sands of Time: Late Miocene Fossils from the Baynunah Formation, U.A.E. (pp. xxx). Cham: Springer.

Whybrow, P. J., \& Hill, A. (Eds.). (1999). Fossil Vertebrates of Arabia, with Emphasis on the Late Miocene Faunas, Geology, and Palaeoenvironments of the Emirate of Abu Dhabi, United Arab Emirates. New Haven: Yale University Press.

\section{FIGURE CAPTIONS}

Fig. 17.1 Map of trackway sites of the Baynunah Formation.

[Width $=1.5$ columns $]$

Figure 17.2 BGH 1 aerial image, without annotation (inset) and with the seven securely identified trackways numbered and labelled. The number after the decimal refers to the print number (stride measurements in Table 17.1). Footprints marked in gray at the intersection of $\mathrm{T} 2$ and $\mathrm{T} 3$ are not confidently attributable to either track. Aerial image acquired December 2017. [Full page width]

Figure 17.3 Stride length data from all measured trackways. Box plots show median, 1st and 3rd quartiles, and whiskers reach the outermost data points within a 1.5 interquartile range. Proboscidean body mass estimates at left were calculated from stride lengths and almost certainly underestimate the true mass of the trackmakers. La, Loxodonta africana; Em, Elephas maximus. The ungulate trackways (far right) were likely made by one or more giraffids. [Half-page width]

Figure 17.4 BIM 4 aerial image unannotated (inset) and labelled, showing the two proboscidean trackways. Acquired December 2010. [Full page width] 
Fig. 17.5 Proboscidean footprints at Jebel Mimiyah (MIM 2). A large number of closelyspaced, circular, micro-laminated, and compressed features bear strong resemblance to the prints at Mleisa 1. A, closeup of prints, showing circular outlines with raised edges with micro-laminated central 'pancake' structures similar to those at Mleisa 1. B, wider view showing a cluster of prints on the eroded surface. Palestinian film director $(1.81 \mathrm{~m})$ for scale. The large outcrop in the distance to the left is MIM 1, from which remains of Stegotetrabelodon (among other taxa) have been recovered. 13 December, 2017. [Full page width]

Figure 17.6. The site of Mleisa 1. A, kite aerial photomosaic. B, outline map. Modified from Bibi et al. (2012) with ungulate trackways now labelled. Imagery acquired January 2011. Also viewable at http://gigapan.com/gigapans/78542 [Full page each, or poster fold-out]

Figure 17.7 Proboscidean footprint morphology at Mleisa 1. A-B, general overview. Note the more erosion-resistant rims of the prints in B. $\mathbf{C}-\mathbf{H}$, closeups of individual footprints. The same print is shown in $\mathrm{C}$ and $\mathrm{D}$, from which a latex mold was made (D). Prints C-G all show a similar morphology, with a convex, dish-shaped top layer which was probably the compressed upper track layer, and a raised rim surrounded by displaced polygons of desiccated algal mat carbonate. [Full page width]

Figure 17.8. The Mleisa 2 ungulate trackway. A, general overview. B, close-up of two prints, scale is $25 \mathrm{~cm}$ long. 20 December 2007. [Full page width]

Figure 17.9. The site of Niqa. A, general view. Note the undulating surface. Numerous round features cover the surface, but none of these were securely identified as prints. $\mathbf{B}$, a single possible footprint of a hippopotamid. 18 December 2007. [Full page width] 
Figure 17.10. A large concentration of proboscidean prints is preserved at Shahriya (SHA 1), but advanced erosion renders these impossible to trace into trackways on the ground. Aerial imagery has yet to be acquired for this site. 12 December 2017. [Full page width] FIGURE 17.9 HERE [Full page width]

Figure 17.11 At UAK 1 are numerous probable proboscidean prints preserved in relief (as pedestals). Presumably the original track layer has been weathered away, and these mounds are leftover infilled structures. Note the regular pace of the prints, suggesting these are a real trackway. 7 January 2011. [One column width] 


\section{TABLE}

Table 17.1 Stride length data (in $\mathrm{cms}$ ) for all measured trackways. Stride lengths of MLS 1 were taken digitally from the corrected photomosaic (Fig. 17.6A, see Bibi et al. 2012), all others are field measurements. Stride numbers match those in Figs. 17.2, 17.4, and 17.6. Stride lengths for the MLS 1 ungulate trackways were not numbered.

\begin{tabular}{|c|c|c|c|c|c|c|c|c|c|c|c|c|c|c|c|c|c|c|c|c|c|}
\hline \multicolumn{22}{|c|}{ BGH1 proboscideans } \\
\hline Stride & T1 & T2 & T3 & T4 & T5 & T6 & T7 & & & & & & & & & & & & & & \\
\hline $1-3$ & 340 & 290 & 248 & 314 & 319 & 250 & 246 & & & & & & & & & & & & & & \\
\hline 3-5 & 335 & 280 & 252 & 334 & 329 & 242 & 220 & & & & & & & & & & & & & & \\
\hline $5-7$ & 326 & 274 & 252 & 333 & 324 & 247 & 220 & & & & & & & & & & & & & & \\
\hline 7-9 & 326 & 297 & & 330 & 322 & & & & & & & & & & & & & & & & \\
\hline $9-11$ & 325 & 292 & & 312 & 315 & & & & & & & & & & & & & & & & \\
\hline $11-13$ & 320 & 303 & & & 330 & & & & & & & & & & & & & & & & \\
\hline 13-15 & 330 & - & & & 317 & & & & & & & & & & & & & & & & \\
\hline $15-17$ & 336 & - & & & 314 & & & & & & & & & & & & & & & & \\
\hline 17-19 & 330 & 295 & & & 350 & & & & & & & & & & & & & & & & \\
\hline $19-21$ & 324 & 295 & & & 320 & & & & & & & & & & & & & & & & \\
\hline 21-23 & 317 & 310 & & & 331 & & & & & & & & & & & & & & & & \\
\hline 23-25 & 326 & 291 & & & & & & & & & & & & & & & & & & & \\
\hline 25-27 & 336 & 300 & & & & & & & & & & & & & & & & & & & \\
\hline 27-29 & 316 & 291 & & & & & & & & & & & & & & & & & & & \\
\hline 29-31 & 318 & 293 & & & & & & & & & & & & & & & & & & & \\
\hline 31-33 & 324 & & & & & & & & & & & & & & & & & & & & \\
\hline \multicolumn{22}{|c|}{ BIM4 proboscideans } \\
\hline Track & T1 & T2 & & & & & & & & & & & & & & & & & & & \\
\hline Stride 1-3 & 291 & 248 & & & & & & & & & & & & & & & & & & & \\
\hline $2-4$ & 278 & 278 & & & & & & & & & & & & & & & & & & & \\
\hline 3-5 & 286 & 267 & & & & & & & & & & & & & & & & & & & \\
\hline 4-6 & 304 & 234 & & & & & & & & & & & & & & & & & & & \\
\hline 5-7 & - & 271 & & & & & & & & & & & & & & & & & & & \\
\hline 6-8 & - & 235 & & & & & & & & & & & & & & & & & & & \\
\hline 7-9 & - & 260 & & & & & & & & & & & & & & & & & & & \\
\hline 8-10 & - & 282 & & & & & & & & & & & & & & & & & & & \\
\hline 9-11 & - & 254 & & & & & & & & & & & & & & & & & & & \\
\hline $10-12$ & - & 247 & & & & & & & & & & & & & & & & & & & \\
\hline $11-13$ & 314 & 312 & & & & & & & & & & & & & & & & & & & \\
\hline $12-14$ & 322 & & & & & & & & & & & & & & & & & & & & \\
\hline 13-15 & 312 & & & & & & & & & & & & & & & & & & & & \\
\hline $14-16$ & 297 & & & & & & & & & & & & & & & & & & & & \\
\hline $15-17$ & 292 & & & & & & & & & & & & & & & & & & & & \\
\hline 16-18 & 303 & & & & & & & & & & & & & & & & & & & & \\
\hline 17-19 & 294 & & & & & & & & & & & & & & & & & & & & \\
\hline $18-20$ & 294 & & & & & & & & & & & & & & & & & & & & \\
\hline \multicolumn{22}{|c|}{ MLS 1 proboscideans } \\
\hline Area & - & - & $\mathbf{A}$ & $\mathbf{A}$ & $\mathbf{A}$ & B & B & B & A & C & D & A & $\mathbf{A}$ & $\mathbf{A}$ & B & $\mathbf{A}$ & $\mathbf{A}$ & $\mathbf{A}$ & B & $\mathbf{A}$ & C \\
\hline Stride & T1 & T2 & T15 & T3 & T13 & T34 & T32 & T10 & T11 & T20 & T27 & T7 & T7b & T6 & T39 & T4 & T41 & T5 & T9 & T16 & T18 \\
\hline $1-3$ & 311 & 324 & 305 & 271 & 283 & 285 & 282 & 268 & 273 & 270 & 276 & 237 & 212 & 260 & 249 & 247 & 258 & 234 & 237 & 248 & 150 \\
\hline $2-4$ & 303 & 330 & 340 & 275 & 297 & 284 & 290 & 284 & 273 & 279 & 278 & 262 & 217 & 231 & 242 & 235 & 237 & 249 & 239 & 240 & 142 \\
\hline 3-5 & 309 & 313 & 349 & 282 & 287 & 287 & 278 & 275 & 277 & 266 & 262 & 278 & 219 & 233 & 261 & 231 & 242 & 268 & 228 & 249 & 145 \\
\hline 4-6 & 326 & 304 & 333 & 314 & 281 & 282 & 275 & 262 & 279 & 272 & 260 & 263 & 275 & 240 & 244 & 270 & 258 & 249 & 242 & 239 & 186 \\
\hline 5-7 & 312 & 318 & 305 & 298 & 276 & 278 & 279 & 265 & 278 & 265 & 268 & 241 & 280 & 217 & 242 & 248 & 247 & 239 & 232 & 234 & 189 \\
\hline 6-8 & 299 & 292 & 272 & & 274 & 284 & & 278 & 284 & 268 & 264 & 235 & 256 & 239 & 253 & & 245 & 232 & 231 & 247 & 177 \\
\hline 7-9 & 315 & 324 & 265 & & 281 & 299 & & 264 & 273 & 274 & 261 & 237 & 262 & 245 & 256 & & 235 & 243 & 233 & 226 & 187 \\
\hline $8-10$ & 307 & 348 & 275 & & & & & 255 & 279 & 270 & 250 & & & 244 & & & & & & 242 & 195 \\
\hline 9-11 & 303 & 322 & 312 & & & & & 267 & 283 & 270 & 258 & & & 227 & & & & & & 267 & 178 \\
\hline
\end{tabular}




$\begin{array}{lllllllll}\mathbf{1 0}-12 & 310 & 305 & 296 & 274 & 286 & 260 & 273 & 239 \\ \mathbf{1 1 - 1 3} & 320 & 310 & 270 & 267 & 280 & 262 & 270 & 268 \\ \mathbf{1 2 - 1 4} & & & & & & & & \\ \mathbf{1 3 - 1 5} & & & & & & & & \\ \mathbf{1 4 - 1 6} & & & & & & & & \\ \mathbf{1 5 - 1 7} & & & & & & & & \\ \end{array}$

MLS 1 ungulates

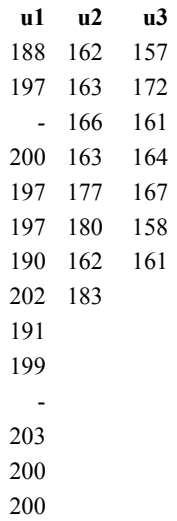

\section{MLS2 ungulate}

Stride

T1

1-3

$2-4$

3-5 143

4-6 153

5-7 184

6-8 182

7-9 189

8-10 205

9-11 185

10-12 174

11-13 200

12-14 192

13-15 183

14-16 192

15-17 196

16-18 197

17-19 200

18-20 190

19-21 193

20-22 194

21-23 189

22-24 195

23-25 187

24-26 188

25-27 193

26-28 190

27-29 188

28-30 188

29-31 191

30-32 198

31-33 201 
Fig 17.1

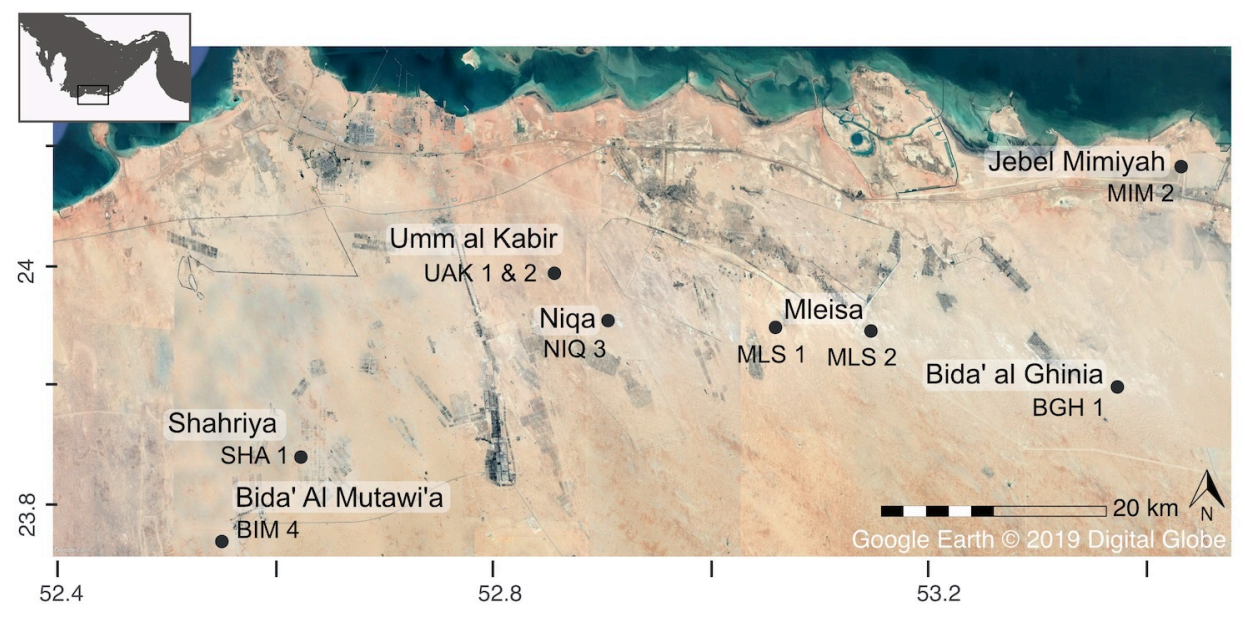


Fig 17.2

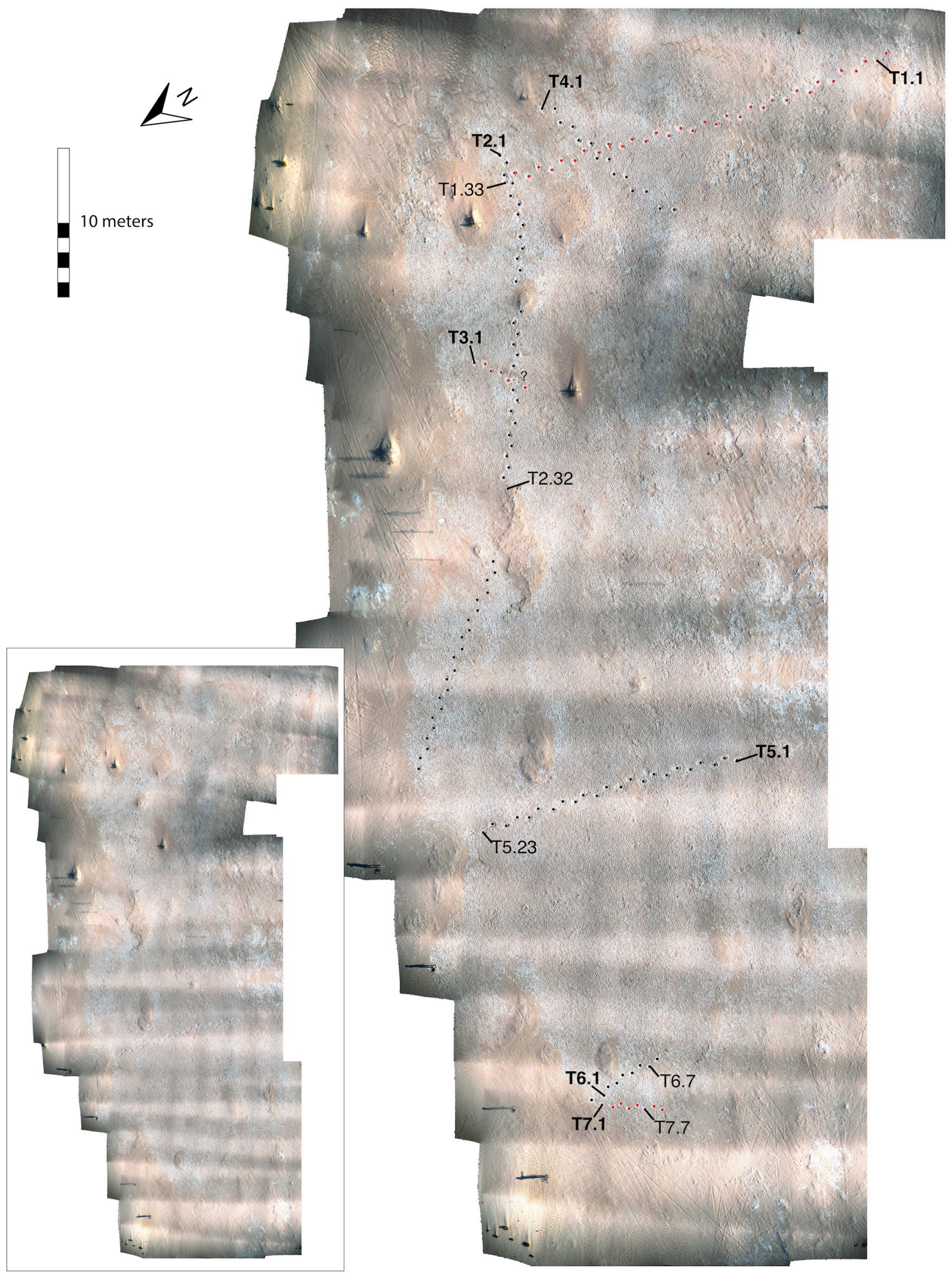


Fig 17.3

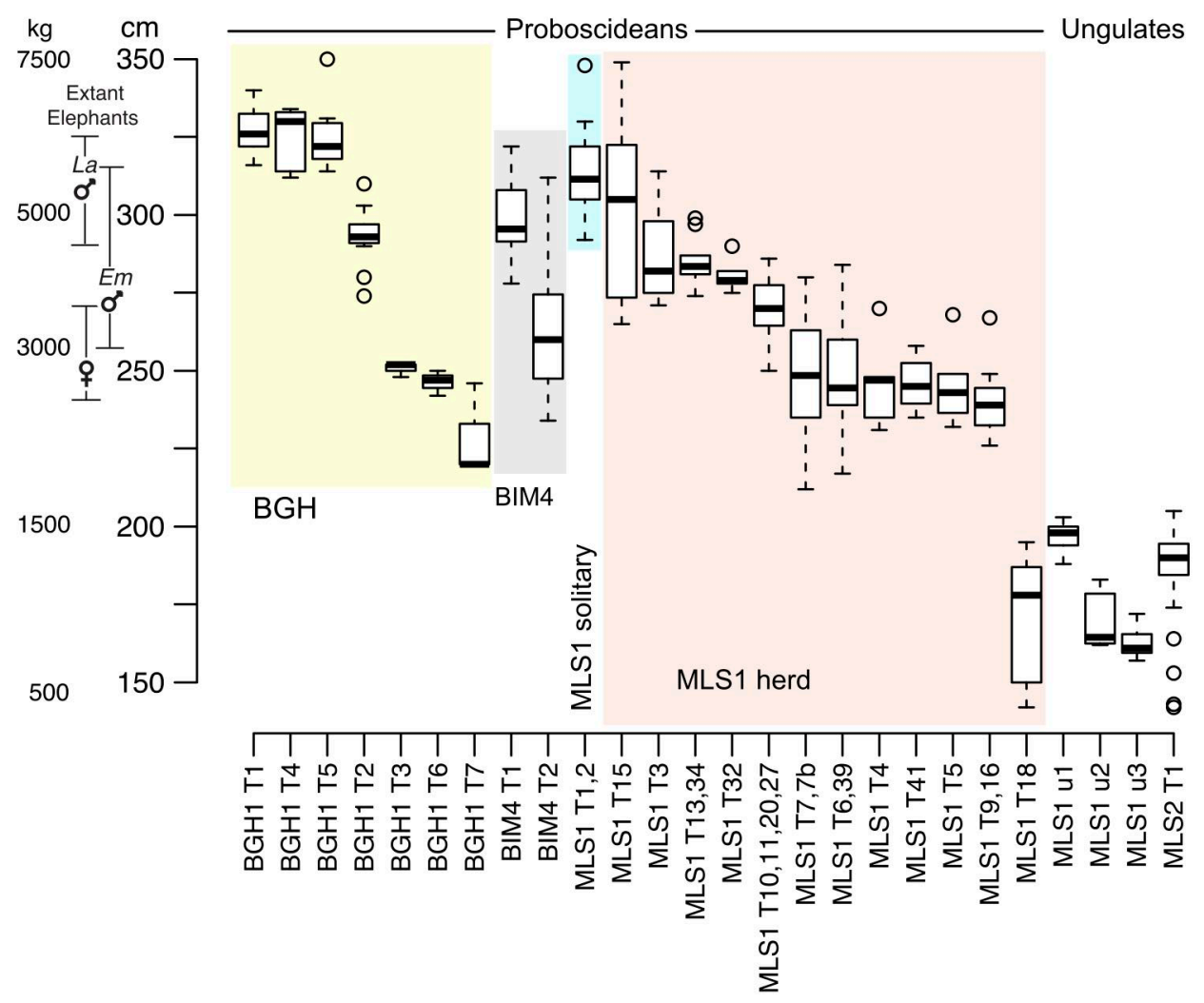


Fig 17.4

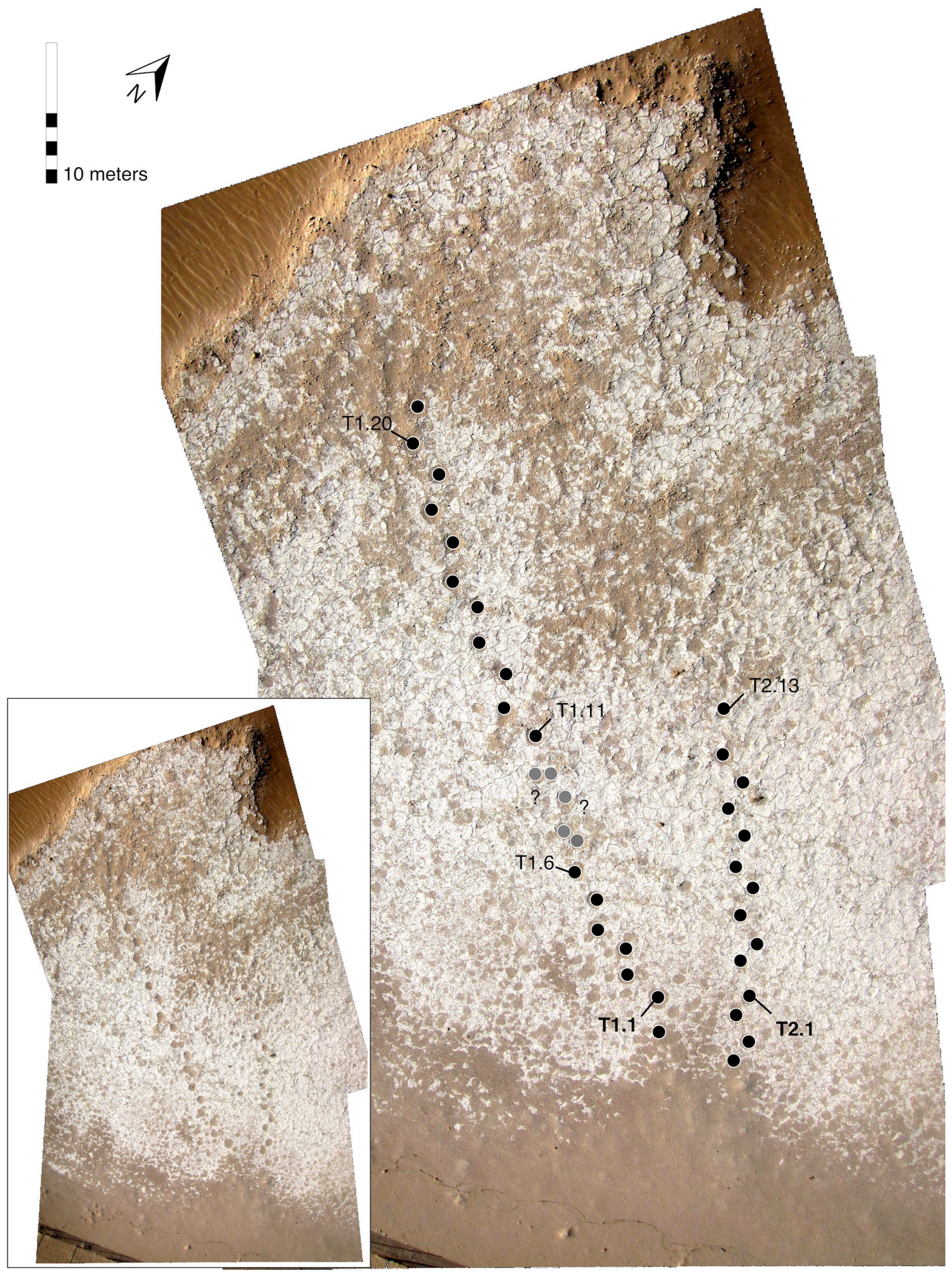


Fig 17.5
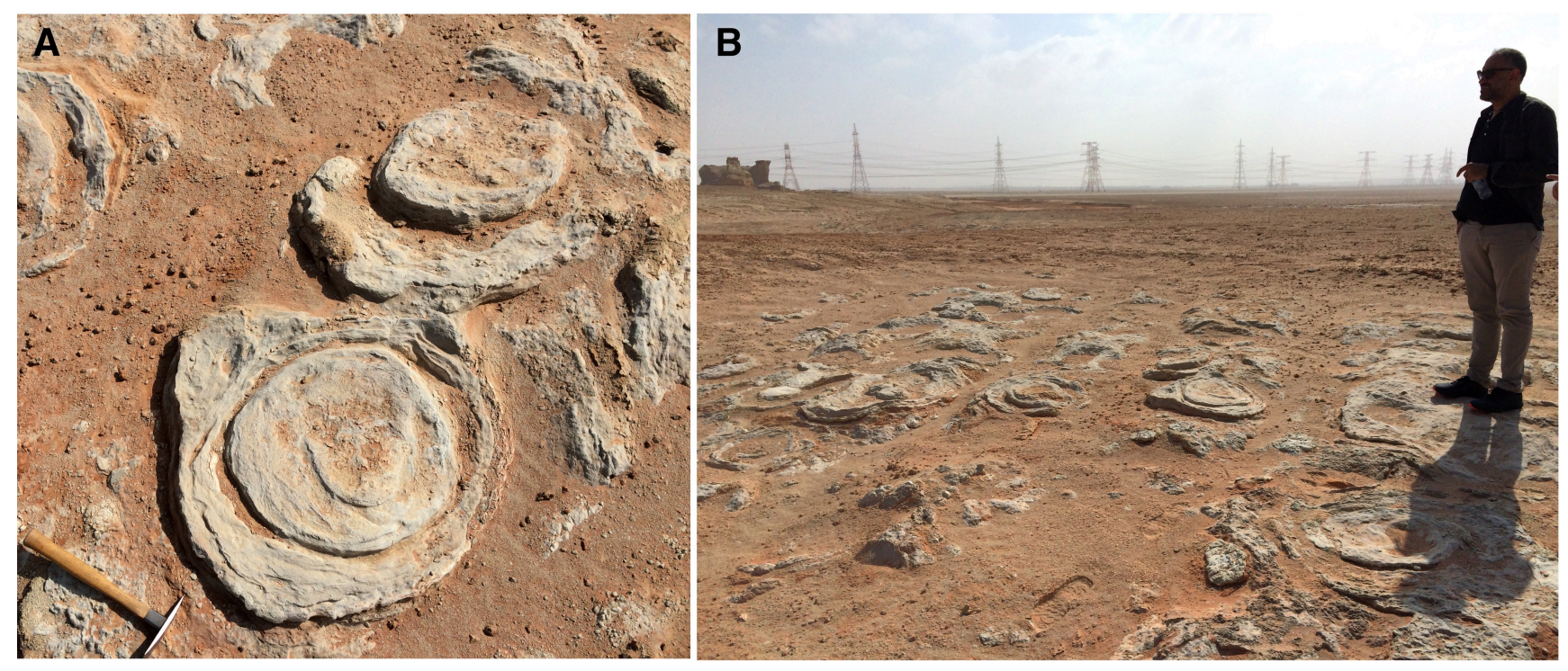


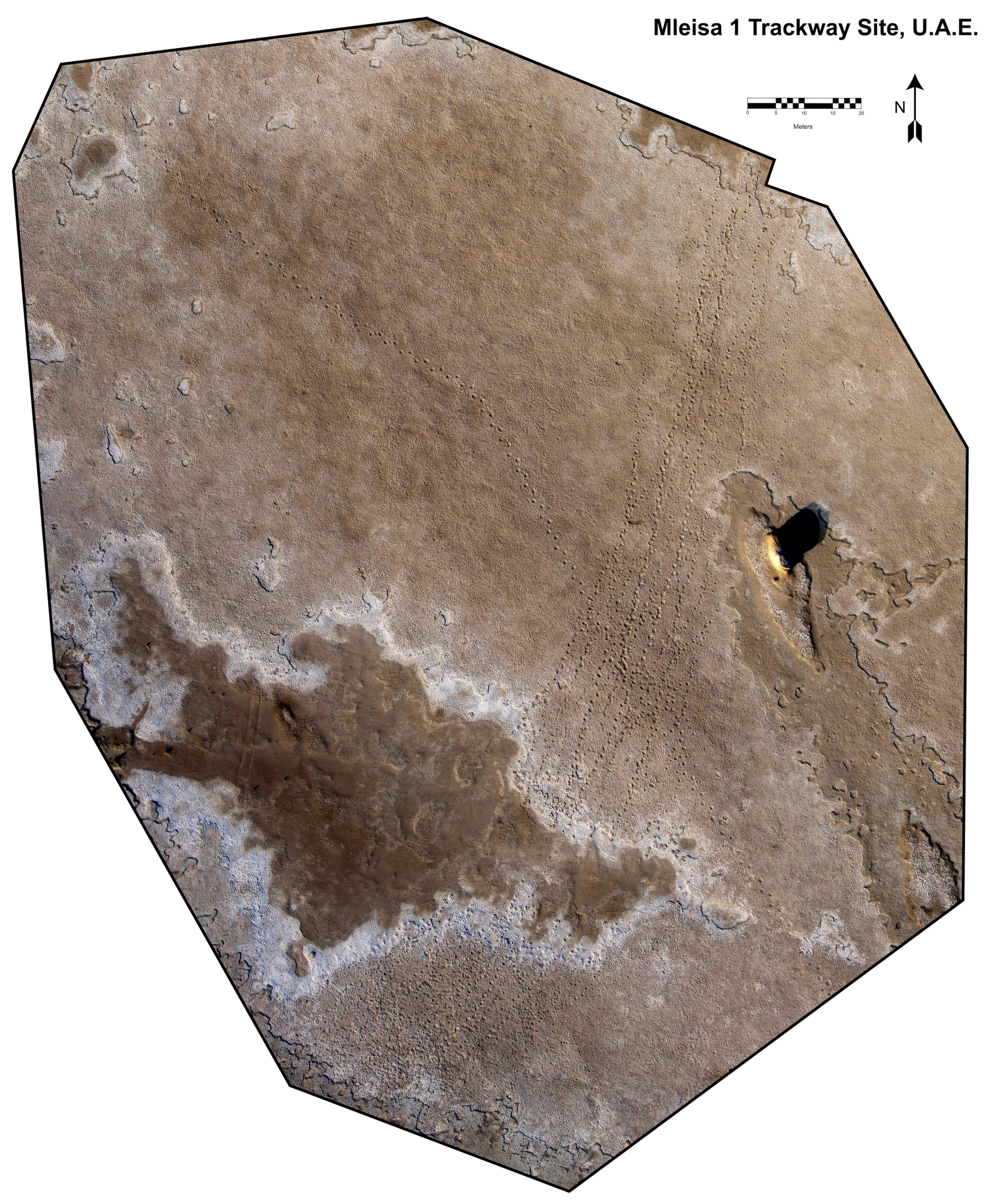


Fig 17.6B

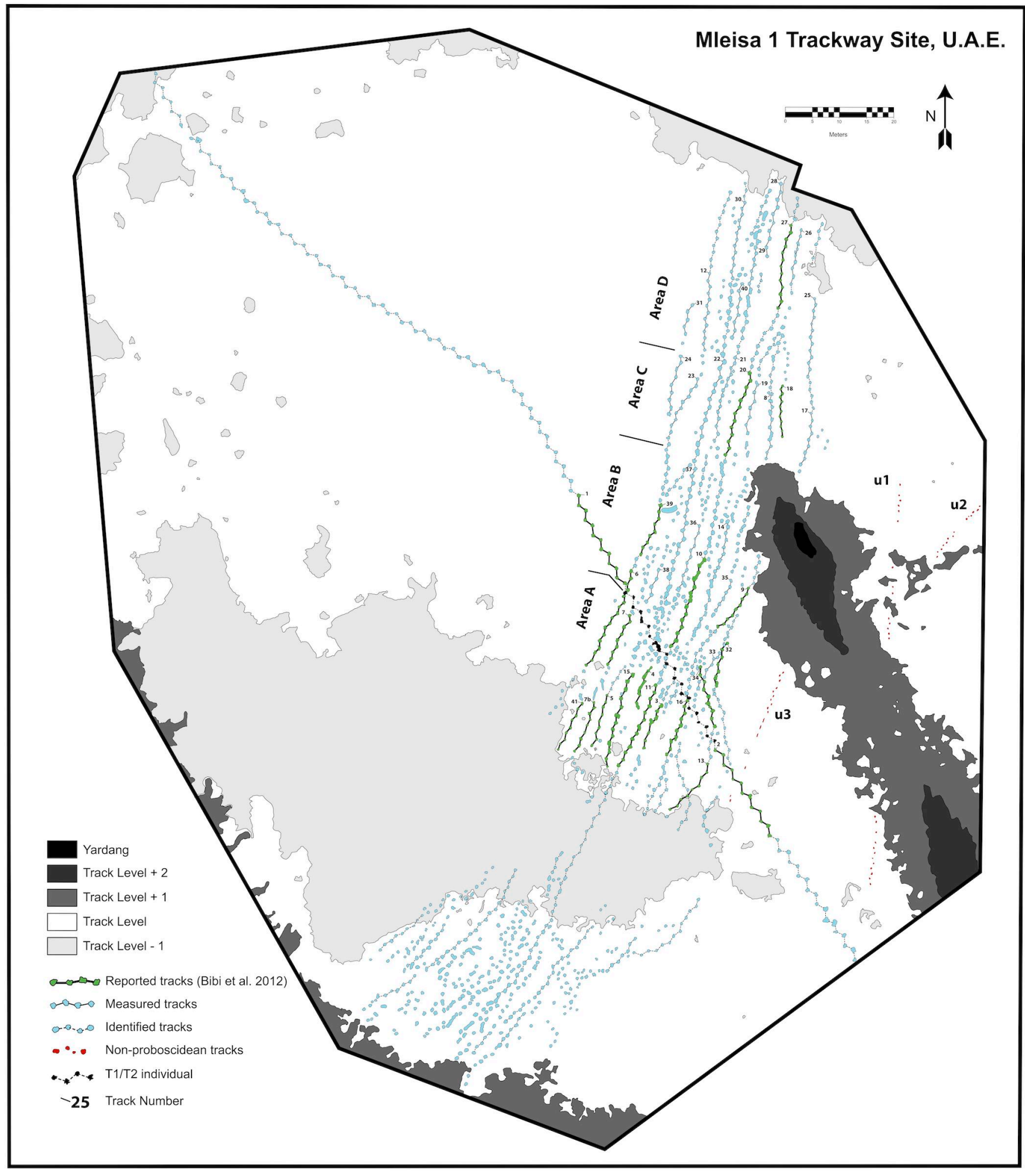


Fig 17.7

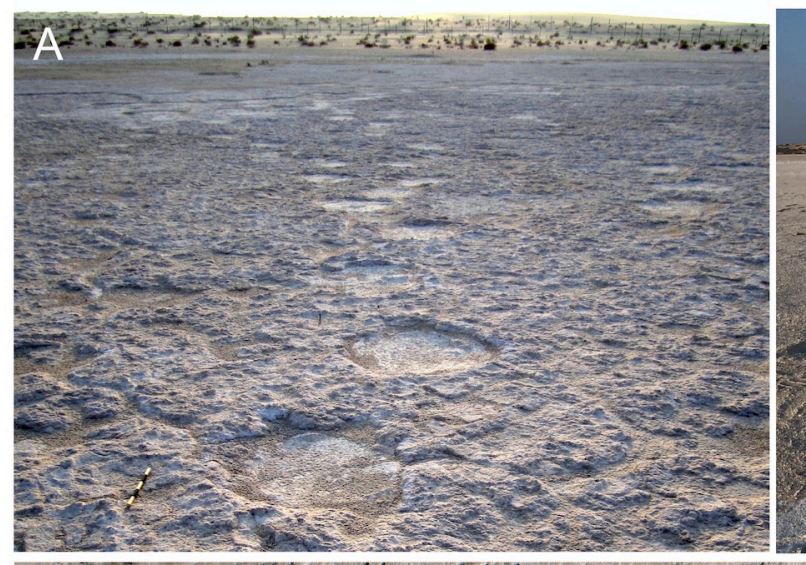

B
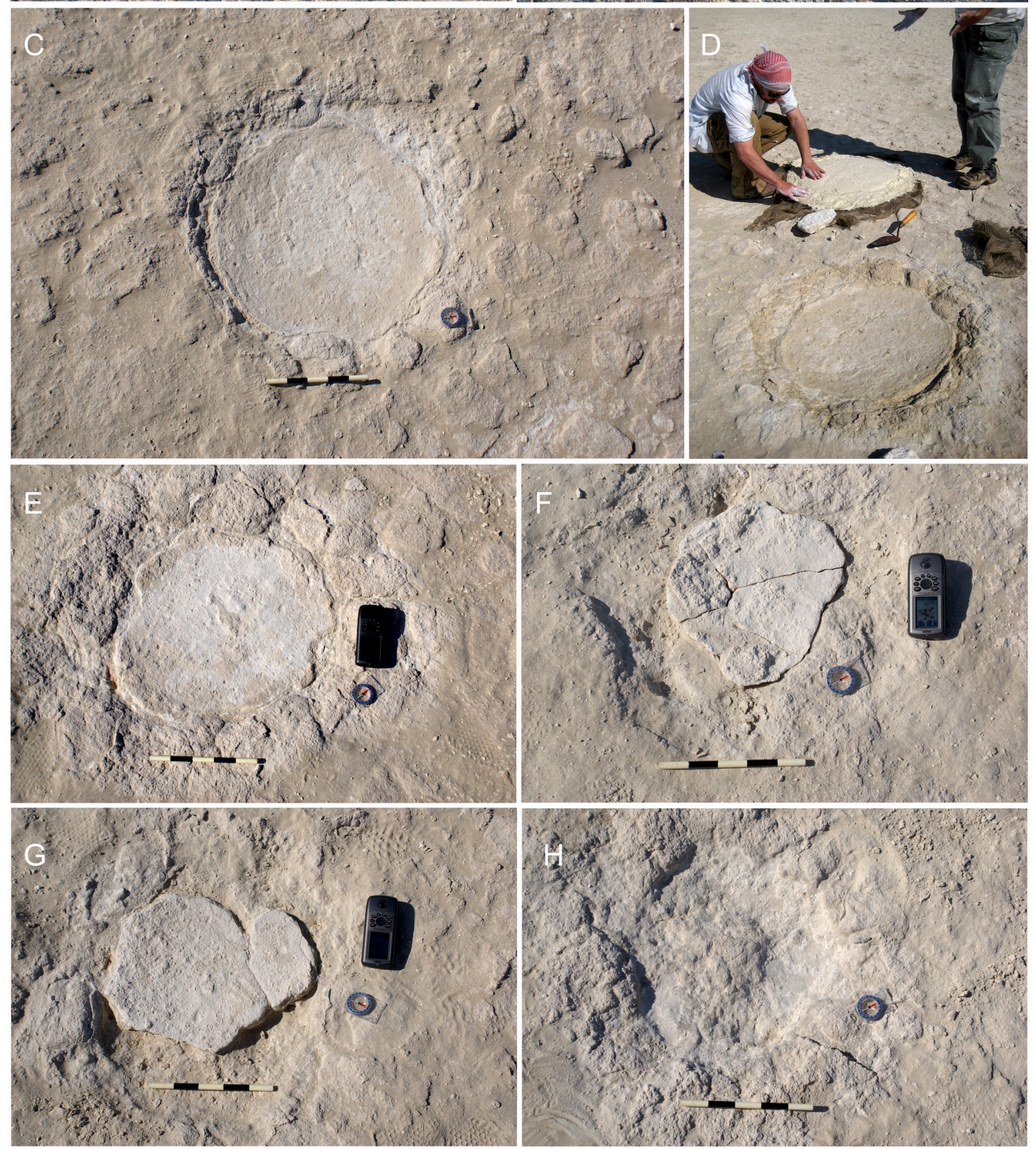
Fig 17.8
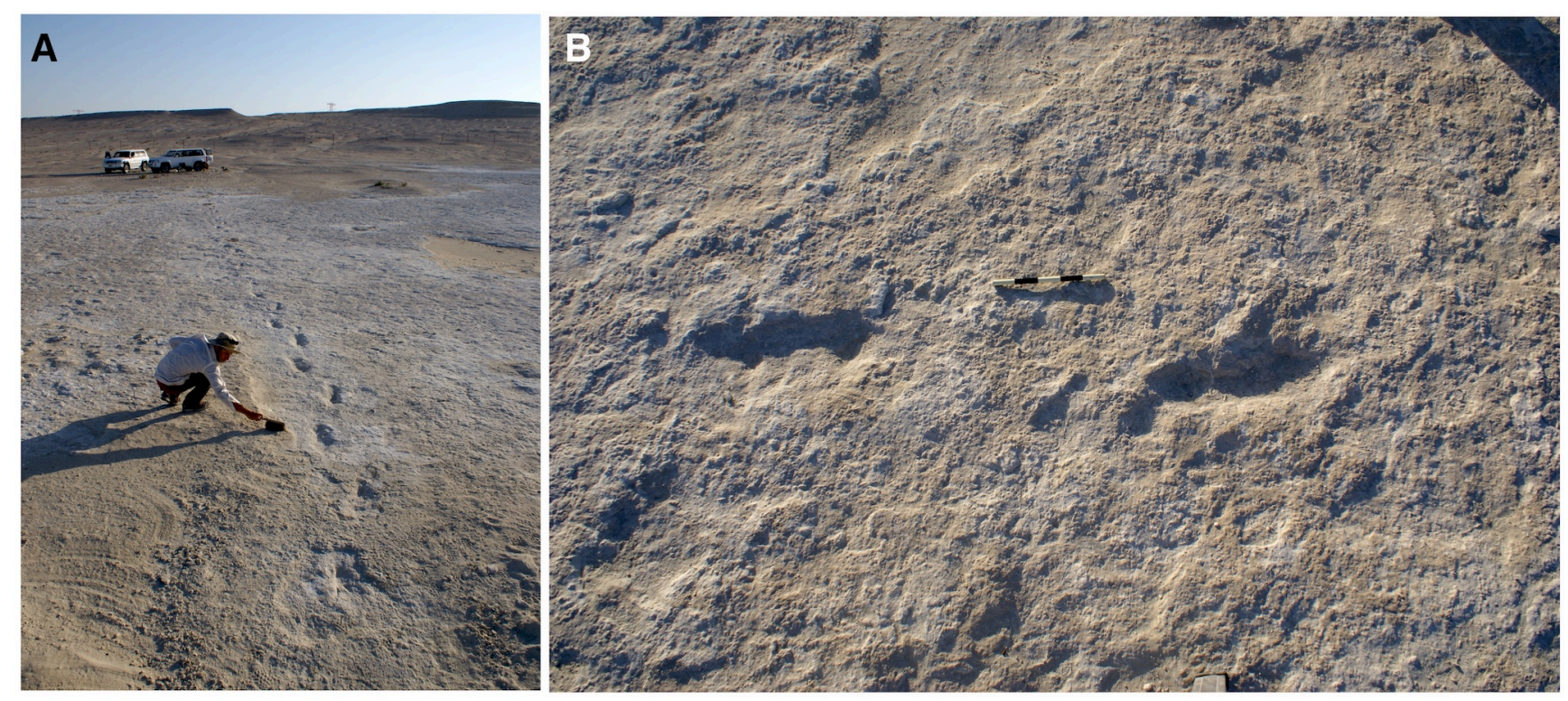
Fig 17.9

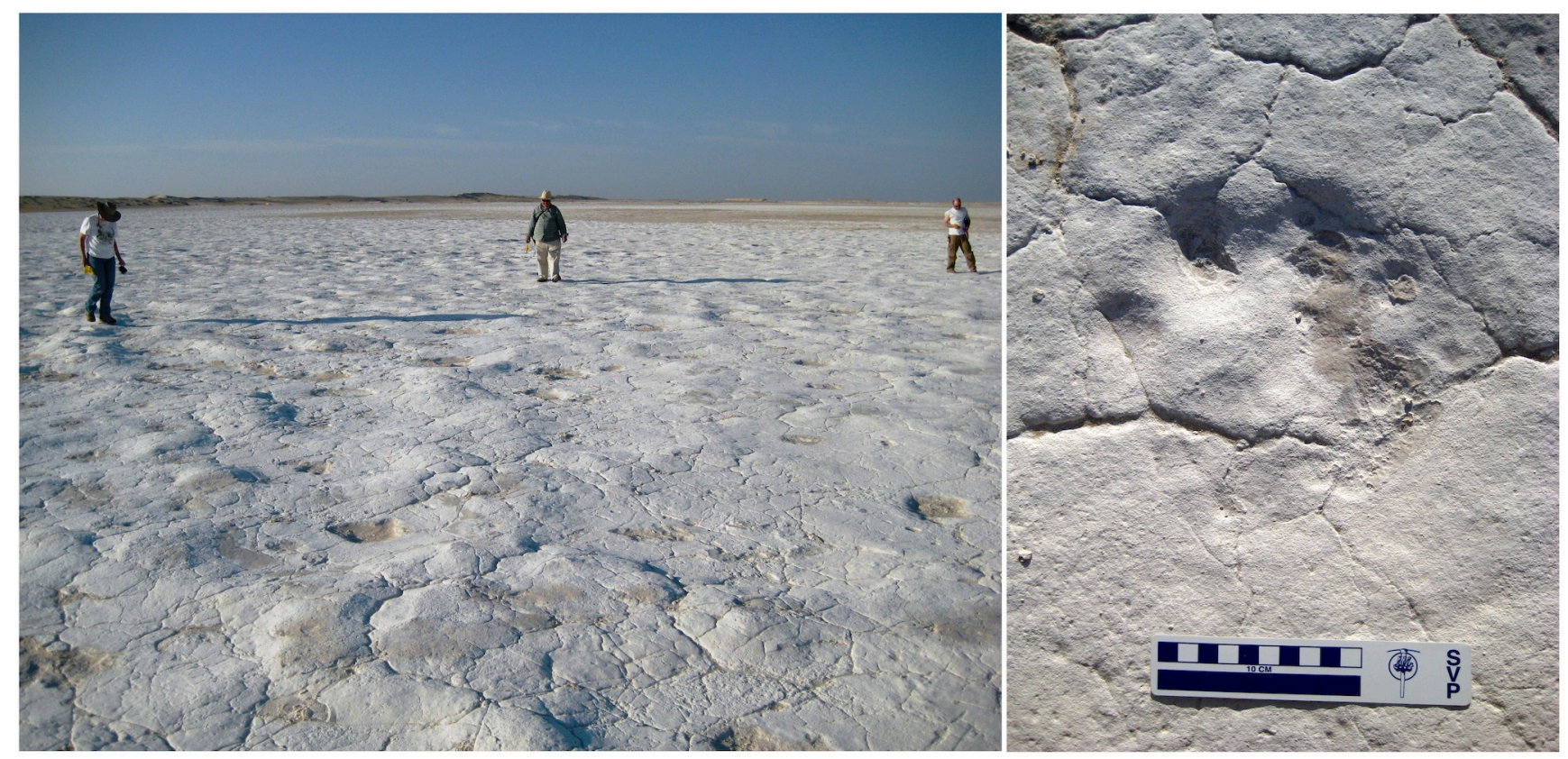


Fig 17.10

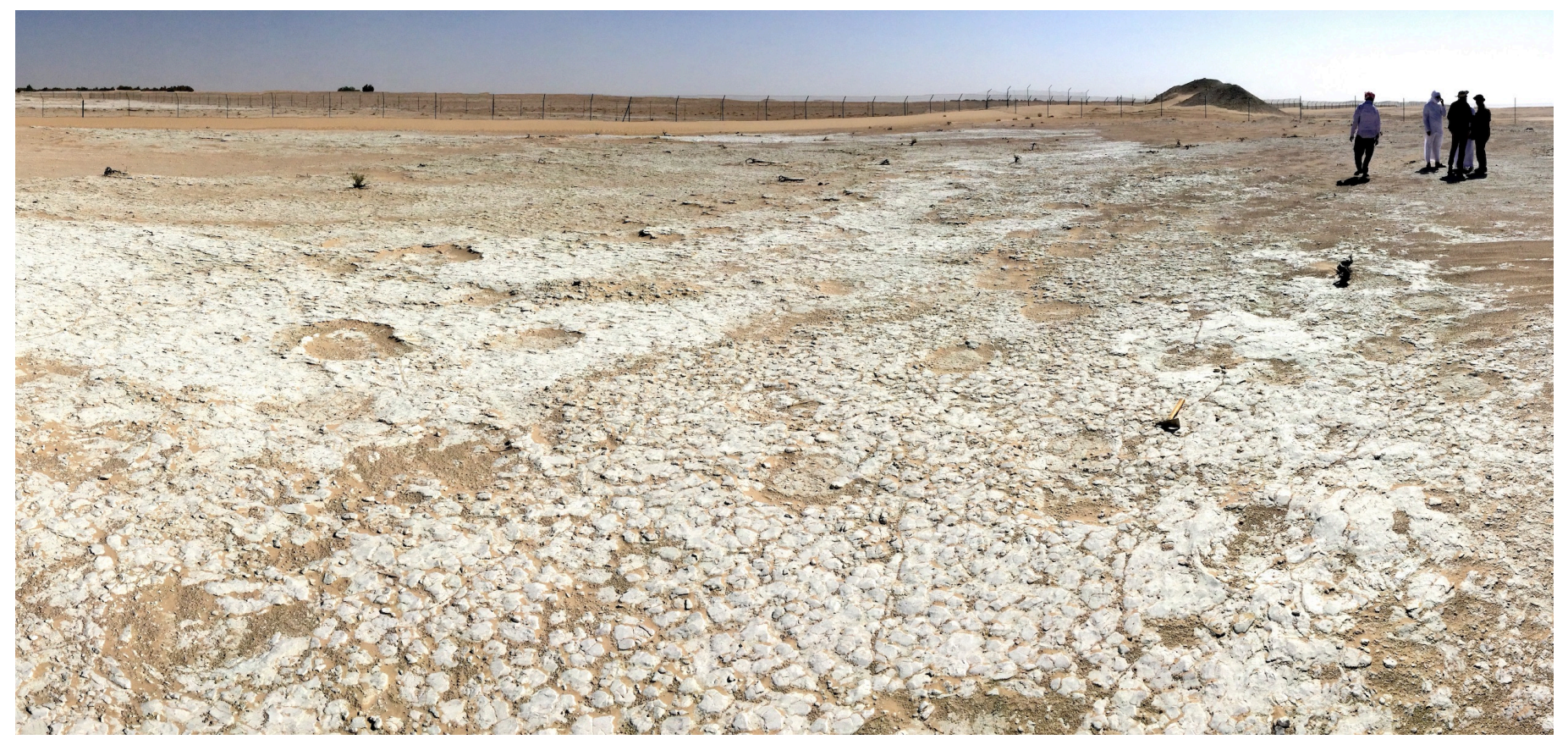


Fig 17.11

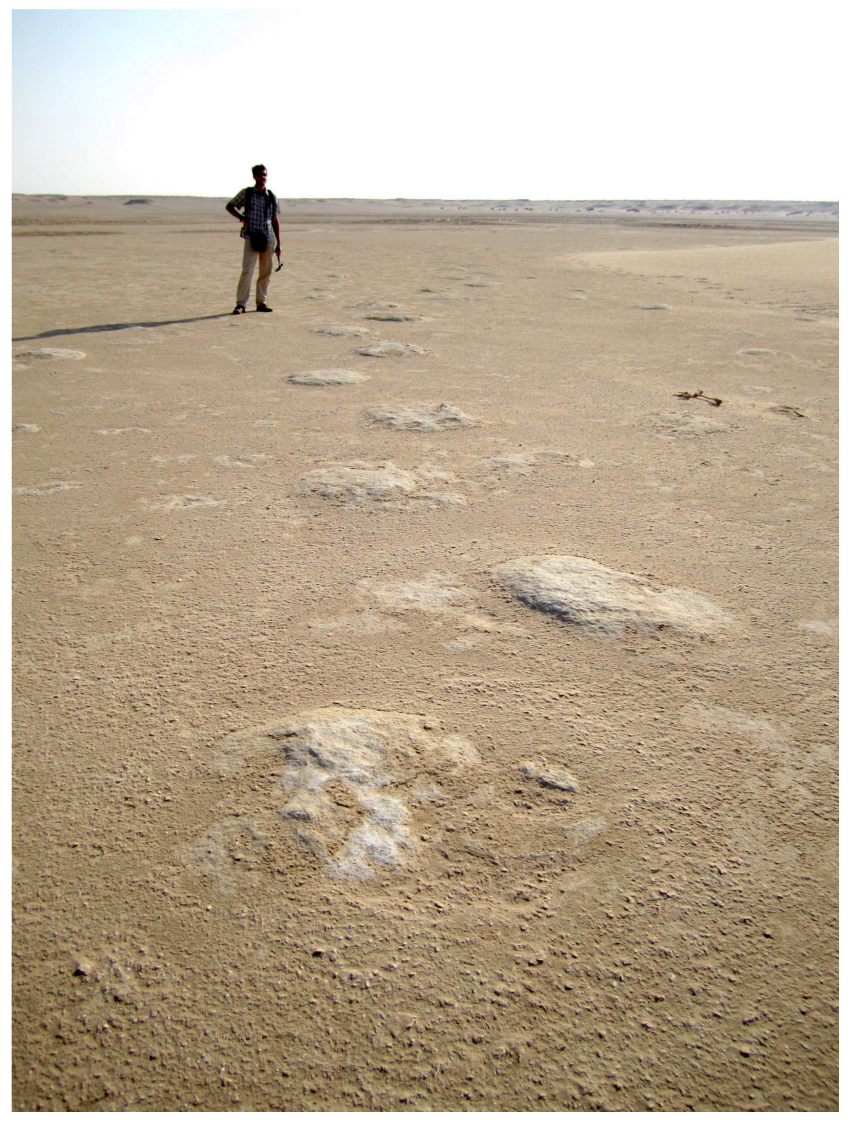

